\title{
Disability in people clinically at high risk of psychosis
}

Eva Velthorst, Dorien H. Nieman, Don Linszen, Hiske Becker, Lieuwe de Haan, Peter M. Dingemans, Max Birchwood, Paul Patterson, Raimo K. R. Salokangas, Markus Heinimaa, Andreas Heinz, Georg Juckel, Heinrich Graf von Reventlow, Paul French, Helen Stevens, Frauke Schultze-Lutter, Joachim Klosterkötter, Stephan Ruhrmann, on behalf of the EPOS group

\section{Background}

Decline in social functioning occurs in individuals who later develop psychosis.

\section{Aims}

To investigate whether baseline differences in disability are present in those who do and those who do not make a transition to psychosis in a group clinically at high risk and whether disability is a risk factor for transition.

\section{Method}

Prospective multicentre, naturalistic field study with an 18month follow-up period on 245 help-seeking individuals clinically at high risk. Disability was assessed with the Disability Assessment Schedule of the World Health Organization (WHODAS-II).

\section{Results}

At baseline, the transition group displayed significantly greater difficulties in making new friends $(z=-3.40$, $P=0.001)$, maintaining a friendship $(z=-3.00, P=0.003)$, dealing with people they do not know $(z=-2.28, P=0.023)$ and joining community activities $(z=-2.0, P=0.05)$ compared with the non-transition group. In Cox regression, difficulties in getting along with people significantly contributed to the prediction of transition to psychosis in our sample $(\beta=0.569$, s.e. $=0.184$, Wald $=9.548, P=0.002$, hazard ratio $(H R)=1.767$, 95\% Cl 1.238-2.550).

\section{Conclusions}

Certain domains of social disability might contribute to the prediction of psychosis in a sample clinically at high risk.

\section{Declaration of interest}

None.
Psychotic disorders are associated with multiple social disabilities in work, study, independent living, interpersonal relations and self-care, ${ }^{1-4}$ and serious disability in functioning is one of the core features of the DSM-IV diagnosis of schizophrenia. ${ }^{2}$ Disability refers to the limitations in an individual's ability to perform the expected socially and culturally defined roles and tasks. ${ }^{5}$ In schizophrenia, disability is thought to be mainly associated with negative symptoms and neurocognitive and social cognitive deficits. ${ }^{6,7}$

Functional decline has been found to occur before the first psychotic episode. In retrospective studies, Häfner et $a l^{8}$ and Larsen et $a l^{9}$ found that deficits were already noticeable in the prodromal and premorbid phase of schizophrenia, respectively. Assessment scales frequently employed in prospective studies and developed for detecting individuals at an ultra-high risk of psychosis include the criterion of impaired functioning connected with genetic risk, as defined by either family history of psychosis or schizotypical personality disorder in the index person. ${ }^{10,11}$ Preliminary findings from recent studies indicate that decline in functioning may be a predictor of psychosis transition. However, these studies mainly focused on social contacts. ${ }^{7,8,12-14}$

In the present 18-month follow-up study of a large European population of individuals clinically at high risk of psychosis, disability was investigated in more detail by examining the following six domains: understanding of and interaction with the world; moving and getting around; self-care; getting along with people; life activities; and participation in society. In line with the major focus of this multicentred, prospective naturalistic field study to identify risk factors for the transition from prodrome to a first psychotic episode,$^{15}$ the aim of the present analyses is to investigate: first, differences in disability at baseline between those who do and those who do not make the transition to psychosis in a group at high clinical risk. And second, whether disability is a risk factor for transition to a first psychosis. For exploratory purposes, we further sought to investigate the association between social disability and clinical symptomatology. We hypothesised that the transition group would display significantly greater disability at baseline than the non-transition group.

\section{Method}

\section{Recruitment}

Between August 2002 and April 2006, data were collected from 245 help-seeking individuals (age 16-35) who met ultra-high-risk and/ or 'cognitive disturbances' criteria and agreed to participate in the European Prediction of Psychosis Study (EPOS) ${ }^{15,16}$ (Fig. 1). The European Prediction of Psychosis Study is a European collaboration of six centres in four countries: Germany, Finland, The Netherlands and the UK. Referral to the early detection services came from psychiatrists, psychologists, general practitioners, outreach clinics, counselling services, teachers or was self-initiated, among others.

Inclusion criteria comprised ultra-high-risk criteria as assessed by the Structured Interview for Prodromal Syndromes (SIPS $3.0)^{17}$ and cognitive disturbances as assessed by the Bonn Scale for the Assessment of Basic Symptoms - Prediction List (BSABS-P), an abbreviated version of the Schizophrenia Proneness Instrument, Adult version (SPI-A).$^{18}$

The ultra-high-risk approach consists of three alternative criteria:

(a) attenuated psychotic symptoms defined by at least one of the following symptoms with SIPS score 'moderate' to 'severe but not psychotic' (3-5), appearing several times per 


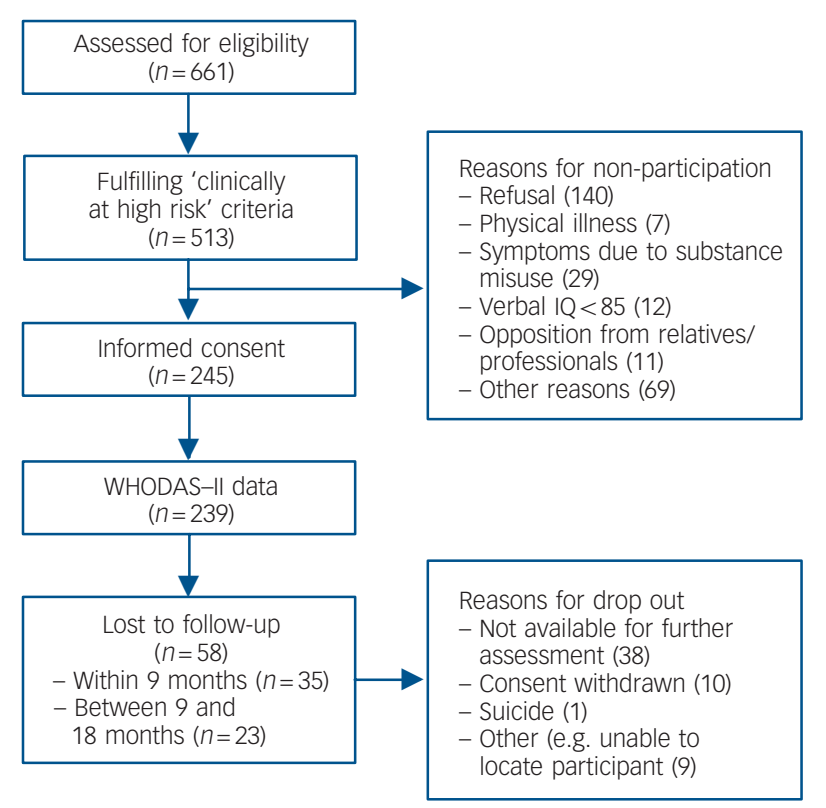

Fig. 1 Flow diagram of participants referred to the European Prediction of Psychosis Study.

week for at least 1 week within the past 3 months: unusual thought content/delusional ideas, suspiciousness/persecutory ideas, grandiosity, perceptual abnormalities/hallucinations, disorganised communication and odd behaviour/appearance;

(b) brief limited intermittent psychotic symptoms (BLIPS) defined by hallucinations, delusions or formal thought disorders occurring within the past 3 months and resolving spontaneously within 1 week scoring 'severe and psychotic' (6) on the SIPS and achieving at least a 'moderate' score on the respective item of the Positive and Negative Syndrome Scale for Schizophrenia; ${ }^{19}$ and

(c) genetic risk and functional deterioration defined by a $30 \%$ or greater reduction on the Global Assessment of Functioning Scale, modified version (GAF-M) ${ }^{17,20,21}$ compared with the highest level of previous functioning for at least 1 month within the previous year in combination with a first- or second-degree relative with a history of any DSM-IV psychotic disorder $^{22}$ or a DSM-IV schizotypal personality disorder of the index person.

The 'cognitive disturbances' criterion requires the presence of at least two of nine cognitive basic symptoms of at least 'moderate' severity $(\geqslant 3)$ during the last 3 months and, independent of severity, first occurrence at least 1 year before intake. The nine basic symptoms were: inability to divide attention, thought interference, pressure, and blockage, disturbances of receptive and of expressive speech, disturbance of abstract thinking, unstable ideas of reference, captivation of attention by details of the visual field.

Exclusion criteria were: a low verbal IQ (IQ $<85)$; past or present psychotic episode lasting longer than 1 week (i.e. fulfilling DSM-IV ${ }^{22}$ criteria of a brief psychotic episode for at least 7 days, assessed by the Structured Clinical Interview for DSM-IV ${ }^{23}$ ); and symptoms relevant for inclusion arising from a known general medical disorder or drugs or alcohol dependency. On account of the naturalistic design of the present study, (prior) use of antipsychotics was not considered an exclusion criterion.
The investigation was carried out in accordance with the latest version of the Declaration of Helsinki. The study design was approved by the medical ethics committees of all participating centres. Informed written consent from participants was obtained after the procedure had been fully explained.

\section{Instruments}

\section{'Clinically at high risk' symptomatology}

The SIPS 3.0, ${ }^{17}$ including GAF-M, was employed to determine the presence, severity and type of ultra-high-risk criteria. The Scale of Prodromal Symptoms (SOPS), the rating scale of the SIPS, has four subscales that include five positive symptom items, six negative symptom items, four disorganisation symptoms items and four general symptom items. All symptoms are rated on a seven-point rating scale anchored from 0 (never, absent) to 6 (severe/extreme - and psychotic for the positive items). Symptomatic criteria for prodromal state are exclusively based on positive symptom items and the disorganisation symptom odd behaviour/appearance.

The EPOS investigators received extensive training from Dr Tandy Miller, one of the SIPS authors, including a reliability check after approximately 6 months. The pair-wise interrater concordance of the SIPS was $77 \%$ and determined acceptable by the training team.

The Bonn Scale for the Assessment of Basic Symptoms Prediction list (BSABS-P) $)^{18}$ was compiled to assess cognitive disturbances. To the item collection of the BSABS-P, three theoretical subscales were defined totalling 33 cognitive, perceptual and motor disturbances assessed on a seven-point severity scale (0-6) with maximum frequency of occurrence during the preceding 3 months as the guiding criterion. The investigators received repeated training by the scale's first author (F. Schultze-Lutter). Concordance rate with expert rating (F.S.L.) was $87.9 \%$.

\section{Disability}

Disability was assessed with the World Health Organization's Disability Assessment Schedule (WHODAS-II). ${ }^{3,24}$ The WHODAS-II assesses disability in individuals irrespective of diagnosis. The nature of disability is rated directly from individuals' responses. ${ }^{24}$ The questionnaire has been conceptually linked to the International Classification of Functioning, Disability and Health, a model of functioning and disability that systematically organises the consequences of disease into three dimensions: body functions and structure, activities, and participation. ${ }^{5}$ The 36 -item interviewer-administered WHODAS-II assesses functioning and disability during the past 30 days and covers the following activity domains:

(a) domain 1: understanding and interacting with the world (six items);

(b) domain 2: moving and getting around (five items);

(c) domain 3: self-care (four items);

(d) domain 4: getting along with people (five items);

(e) domain 5: life activities (eight items):

(i) household activities (four items)

(ii) work activities (four items);

(f) domain 6: participation in society (eight items).

The domain life activities is divided in household activities (four items) and work activities (four items) and because of the small percentage of participants to whom this latter subdomain applied we looked at the subdomain household activities 
separately. In both subdomains, the amount of time spent on the activities was additionally recorded. The scale's general items were rated on a five-point severity scale, i.e. from 1 (no dysfunction) to 5 (serious to maximum dysfunction).

In addition to the scores on each single item and in congruence with Chopra et al, ${ }^{3}$ we determined an average score for each domain, thereby allowing a comparison between groups in the WHODAS-II profiles. Hence, the average score for each participant could range from 1 (indicating no reported difficulty) to 5 (indicating severe difficulty) in each domain. ${ }^{3}$

Until now, no study has been conducted on the specific psychometric properties of the WHODAS-II when used with people at clinically high risk for psychosis. However, the validity of the instrument has been tested in numerous other patient populations, suggesting acceptable internal consistency, test-retest reliability and convergent validity. ${ }^{5,24-26}$ In a validation study of 904 participants across ten different conditions (for example depression), the WHODAS-II has been shown to have good reliability (Cronbach's $\alpha$ ranged from 0.70 to 0.97 for the different subscales). ${ }^{25}$ Further, Chopra et $a l^{24}$ and McKibbin et al ${ }^{27}$ have found the WHODAS-II to have fair test-retest reliability in people with long-term psychotic disorders despite deficiencies in reality testing.

In spite of this demonstrated satisfying reliability, the two items 'getting dressed' and 'problems because of barriers or hindrances in the world around you' were thought to induce equivocal interpretation within our young sample. 'Hindrances in the world around you', for example, may have been misinterpreted as hindrances caused by other people. Only those who interpreted hindrances as physical (for example, hindrances caused by a wheelchair) understood the question correctly. Because of the questionable reliability of these two items in our group, they were not entered in the analyses and not considered further.

\section{Follow-up}

Follow-up assessments with the SIPS and BSABS-P took place at 9 and 18 months. Transition to psychosis was operationalised as a continuation of BLIPS, i.e. any single item on the positive subscale of SIPS (SIPS-Positive) with a score of 6 for more than 7 days. ${ }^{13,28,29}$ Following identification of full-blown psychotic symptoms in the SIPS interview, the diagnostic category on transition was determined by applying DSM-IV criteria ${ }^{22}$ of psychotic disorders and affective disorders with psychotic features. Thereby, the different time threshold of Criterion B of 'brief psychotic disorder' was adapted to the BLIPS definition. Past and present psychosis as parts of the exclusion criteria as well as psychotic diagnosis on transition were assessed with the SCID-I. ${ }^{23}$

\section{Statistical analysis}

Statistical analyses were performed using SPSS (version 16.0.2) for Windows. Comparisons between the transition group and non-transition group were made with Pearson's chi-squared tests and an independent sample $t$-test for the GAF score.

To examine differences in the categorical domains as well as in the separate categorical items of the WHODAS-II, MannWhitney U-tests were used. Kaplan-Meier survival analysis was used to calculate survival time, i.e. time to transition.

The effect of different covariates on time to transition was estimated with the Cox proportional hazard model. In this model, transition to psychosis was entered as the status variable, time to onset of psychosis or to follow-up as the time variable and the weighted sum scores of the WHODAS-II domains (with the exception of work activities) as covariates. Weighted sum scores of each domain were computed by dividing the sum score of all items (except for the items 'getting dressed' and 'problems because of barriers or hindrances in the world around you') with the number of items. Subsequently, these scores were entered into the analysis as ordinal data using the backward Wald method. Treatment was entered as an additional covariate in the model using the blockwise method. The recruiting centre was entered as a stratum variable in the regression model. $P<0.05$ was considered statistically significant. A survival curve was obtained using Kaplan-Meier survival analysis.

Bivariate correlations between social disability and SIPS symptoms were evaluated using Spearman's rank correlation. We adjusted the type I error, i.e. alpha, for multiple testing by dividing the overall alpha level of 0.05 by the number of items. After this correction, $P \leqslant 0.0013$ was considered statistically significant.

\section{Results}

\section{Participant characteristics}

At 18-month follow-up, 37 participants had made a transition to psychosis. The transition group did not differ significantly from the non-transition group in terms of age, gender and drug use. In congruence with results of previous studies, ${ }^{13,15}$ we found a difference in the level of global functioning (GAF score $)$ at baseline $(P<0.005)$, with a significantly lower GAF score in the transition group $(42.4$, s.d. $=1.6)$ compared with the non-transition group $(52.7$, s.d. $=0.8)$.

Only four participants met all three ultra-high-risk criteria, three of whom also met cognitive disturbances criteria. In total 143 participants displayed both ultra-high-risk and cognitive disturbances symptoms, 72 met the ultra-high-risk criteria, and 24 reported only cognitive disturbances symptoms. These three cohorts did not significantly differ in transition rates. The mean time to transition from baseline examination was 496.8 days (s.e. $=8.5,95 \%$ CI 480.2-513.6).

A total of 239 participants completed the WHODAS-II at baseline (131 males, mean age 22.5, s.d. $=5.3)$. Of these, 35 were lost to follow-up at 9 months and altogether 58 at 18 months. Participants did not differ significantly from those lost to follow-up in terms of age, gender, severity of negative symptoms, severity of disability, global functioning and familial risk. However, differences were found on two positive symptom items of the SIPS; those lost to follow-up had a lower score on suspiciousness $(t=-2.07, P=0.040)$ and a higher score on hallucinations at baseline $(t=2.15, \quad P=0.030)$. As regards medication, antidepressants were prescribed to $45(18.8 \%)$ of the 239 participants, antipsychotics to $29(12.1 \%)$ and both antidepressants and antipsychotics to 22 (9.2\%); for $30(12.6 \%)$ participants no reliable information on their medication was available.

\section{Disability}

Online Table DS1 displays the overall scores of the domains as assessed by the WHODAS-II. Within the entire group, the highest disability scores were found in domain 6: participation in society (mean 2.38, s.d. $=0.96$, median 2.29). Mann-Whitney $U$-tests indicate that the baseline ratings of the transition group were significantly higher than those of the non-transition group only in domain 4, getting along with people $(z=-3.03$, $P=0.002)$. This difference was mainly caused by the items making new friends $(z=-3.40, P=0.001)$, maintaining a friendship $(z=-3.00, P=0.003)$ and dealing with people you do not know $(z=-2.28, P=0.023)$. 
Although no significant difference was found for average scores in domain 6, participation in society, a difference was found within its component item, joining community activities $(z=-2.0, P=0.05)$, with the transition group reporting more difficulties in this area.

Questions related to work activities could not be answered by $33 \%$ of the participants (37\% of the transition group and $31 \%$ of the non-transition group), mostly because of participants not having been employed or otherwise working (i.e. self-employed, studying, in school or training or doing housework etc.) in the past 30 days before the interview. For the remaining participants, the difference between the two groups in number of hours spent on work or study is approaching significance $(t=-1.93$, $P=0.056$ ), with the transition group working less total hours than the non-transition group. The amount of missing data because of the absence of work/study in the subdomain work activities rendered further interpretation of this section impracticable.

\section{Cox regression analysis}

The backward stepwise Cox proportional hazard model was used to identify the predictive value of the weighted sum scores of the six domains, except for the subdomain work activities. In this analysis, domain 4 , getting along with people, was retained in the model as a predictor of a first psychotic episode $(\beta=0.672$, s.e. $=0.187$, Wald $=12.964, P<0.001$, hazard ratio $(H R)=1.958$, 95\% CI 1.358-2.822). Thus the relative risk of developing a psychosis nearly doubled with increasing difficulties in contact with other people. None of the other covariates further contributed independently to the prediction of a first psychotic episode.

Adding treatment to the model, the use of antipsychotics $(\beta=-1.682, \quad$ s.e. $=0.534, \quad P=0.002) \quad$ and antidepressants $(\beta=-2.125$, s.e. $=0.743, P=0.004)$ were kept in the equation. Domain 4, getting along with people, continued to contribute significantly to the equation, and the change in hazard ratio was only minor $(\beta=0.569$, s.e. $=0.184$, Wald $=9.548, \quad P=0.002$, $\mathrm{HR}=1.767,95 \%$ CI $1.238-2.550)$.

The survival curves of the two disability groups for the domain getting along with people are presented in Fig. 2; the rate of transition differed significantly between the group with moderate to severe disability $(n=72)$ and the group with no to mild disability $(n=167)$ in this domain $\left(\chi^{2}=11.91, P=0.001\right)$.

\section{Spearman's rank correlation}

Table 1 displays the correlations between symptoms as assessed with the SIPS and social disability before $(P<0.05)$ and after Bonferroni adjustment $\left(P_{\text {adjusted }}<0.0013\right)$. We found disability in the fourth domain, getting along with people, and the sixth domain, participation in society, to be related to both negative and general symptoms of the SIPS. Although not surviving Bonferroni adjustment, there was an additional association between social disability and the SIPS positive item suspiciousness. The highest correlations, however, were found between getting along with people and the negative symptom social anhedonia and withdrawal as well as between participation in society and the general symptom dysphoric mood.

\section{Discussion}

In the present study on the role of disability in the transition to psychosis, we employed a validated and reliable questionnaire to measure a wide range of disability in a large sample of young people clinically at high risk for a psychosis. To our knowledge, our study is not only the first prospective study to use the

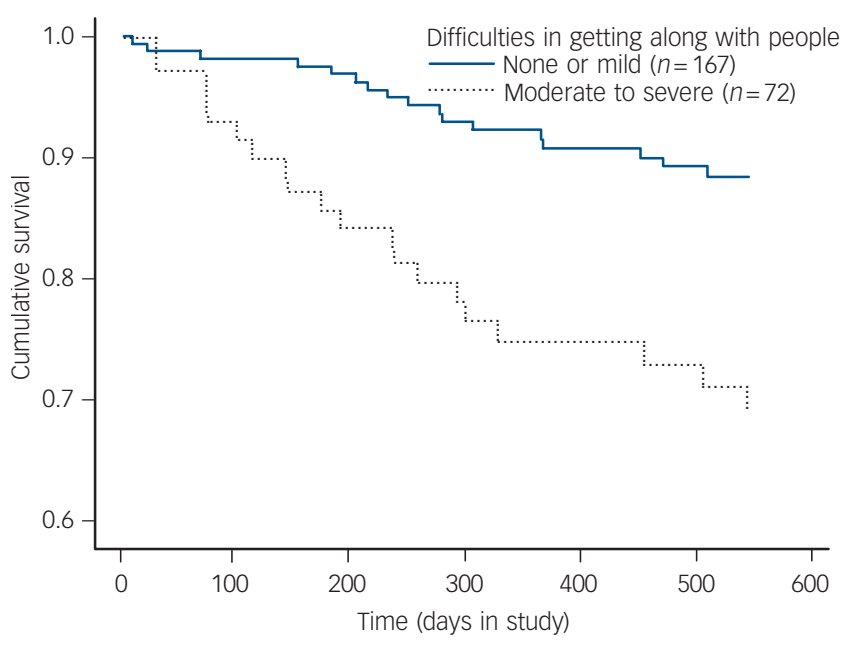

Fig. 2 Survival analysis for 18-month follow-up $(n=239)$.

WHODAS-II in a large clinical high-risk sample but also the first prospective study that in detail examined disability as a risk factor of a transition to psychosis. As expected, we found that within this help-seeking population, the transition group was experiencing significantly greater social disability at baseline compared with the non-transition group.

Difficulties in the domain getting along with people appeared to contribute most to the prediction of the onset of a first psychotic episode within a study of people clinically at high risk. Within this category, developing or maintaining friendships appeared to be particularly problematic for those later developing psychosis, since those who made a transition reported significantly greater difficulties at baseline in both developing and maintaining friendships compared with those who did not make the transition. Although we only compared disability in cross-section, such difficulties may well be progressive. In a representative group of young people with early-onset psychosis, Boeing et al ${ }^{30}$ found that up to $82 \%$ of the sample experienced a moderate to severe 'lack' of friendships during their first psychotic episode. This is a noteworthy finding, since strong social networks are related to both better health status and better quality of life. ${ }^{31}$

Furthermore, our correlation analyses suggest that social disability in individuals clinically at high risk may be mainly related to negative and general symptoms although a modest association was found between social disability and the positive SIPS item suspiciousness. Difficulties in getting along with people showed high correlations with negative symptoms, and disturbances in participating in society were mainly associated with general symptoms such as dysphoric mood. Since recent studies have found strong associations between negative symptoms and transition to psychosis in a sample clinically at high risk, ${ }^{13,14}$ it is not surprising that difficulties in getting along with people was the best predictor of a first psychotic episode in our sample.

Our findings on social disability in our sample are also in line with previous studies of individuals clinically at high risk, in which transition was associated with more severe social anhedonia and withdrawal. ${ }^{13,14,32,33}$ In a retrospective study, participants diagnosed with schizophrenia frequently increasingly lagged behind their healthy peers in social development from an early, pre-psychotic state on. ${ }^{8,34}$ Using the Premorbid Adjustment Scale, Shapiro et $a l^{35}$ found social abnormalities in childhood even before the age of 11 . 
Table 1 Spearman's rank order correlations between social disability and clinical syndromes $(n=239)$

\begin{tabular}{|c|c|c|c|c|}
\hline \multirow[b]{2}{*}{ Measures $^{a}$} & \multicolumn{2}{|c|}{ Getting along with people ${ }^{\mathrm{b}}$} & \multicolumn{2}{|c|}{ Participation in society ${ }^{\mathrm{b}}$} \\
\hline & Rho & $P$ & Rho & $P$ \\
\hline P1. Unusual thought content/delusional ideas & 0.11 & 0.11 & 0.24 & 0.71 \\
\hline P2. Suspiciousness/persecutory ideas & 0.20 & $0.002^{*}$ & 0.17 & $0.008^{*}$ \\
\hline P3. Grandiose ideas & -0.01 & 0.90 & -0.05 & 0.44 \\
\hline P4. Perceptual abnormalities/hallucinations & -0.003 & 0.97 & 0.05 & 0.41 \\
\hline P5. Disorganized communication & 0.09 & 0.15 & 0.14 & 0.04 \\
\hline N1. Social anhedonia and withdrawal & 0.36 & $<0.001^{* *}$ & 0.29 & $<0.001 * *$ \\
\hline N2. Avolition & 0.24 & $<0.001^{* *}$ & 0.33 & $<0.001 * *$ \\
\hline N3. Decreased expression of emotion & 0.30 & $<0.001 * *$ & 0.23 & $<0.001 * *$ \\
\hline N4. Decreased experience of emotions and self & 0.23 & $<0.001^{\star *}$ & 0.17 & $0.01 *$ \\
\hline N5. Decreased ideational richness & 0.09 & 0.16 & 0.08 & 0.20 \\
\hline N6. Deterioration in role functioning & 0.24 & $<0.001 * *$ & 0.29 & $<0.001 * \star$ \\
\hline D1. Odd behaviour or appearance & 0.22 & $0.001^{* *}$ & 0.17 & $0.008^{*}$ \\
\hline D2. Bizarre thinking & 0.17 & $0.01^{*}$ & 0.09 & 0.16 \\
\hline D3. Trouble with focus and attention & 0.17 & $0.009 *$ & 0.22 & 0.001 ** \\
\hline D4. Personal hygiene/social attentiveness & 0.16 & 0.02 & 0.12 & 0.06 \\
\hline G1. Sleep disturbance & 0.16 & $0.01 *$ & 0.21 & 0.001 ** \\
\hline G2. Dysphoric mood & 0.27 & $<0.001 * *$ & 0.36 & $<0.001 * *$ \\
\hline G3. Motor disturbances & 0.18 & $0.006^{*}$ & 0.27 & $<0.001 * *$ \\
\hline G4. Impaired tolerance to normal stress & 0.27 & $<0.001^{\star *}$ & 0.34 & $<0.001^{* *}$ \\
\hline
\end{tabular}

These studies suggest that social deficits may precede positive ultra-high-risk symptoms. Such deficits may be caused by the early onset of attenuated negative symptoms as suggested by the clinical high-risk model of Cornblatt et al. ${ }^{36}$ Negative and general affective symptoms may cause the adolescent to withdraw from increasingly demanding and complex social contacts when adult roles have to be taken up. ${ }^{8}$ In addition, the reported negative attitude of others when the individual is in the clinically at high risk phase $^{37}$ may also contribute to this social withdrawal. Irrespective of the possible nature of any interaction between negative and positive symptoms and social disability, poor premorbid social functioning has been related to elevated risk and poor outcomes in psychotic disorders, ${ }^{6}$ thus making it a significant target for an early intervention in the at-risk state. Improving social functioning, for example through cognitivebehavioural therapy in the clinically at high risk period, may protect the adolescent or young adult from social isolation, and maintaining reality testing with peers may reduce the risk of later delusional ideation.

In addition, to improve psychosis prediction, an assessment of disability in people clinically at high risk may be relevant in identifying important needs, for both the individual and their families. ${ }^{38}$ Help in meeting these needs through appropriate early intervention is likely to also improve the quality of life of individuals clinically at high risk and, thereby, to diminish the likelihood of transition to psychosis.

\section{Limitations}

In spite of the outlined strengths of our study, some critical issues regarding the use of the WHODAS-II in a clinically at high risk sample need to be addressed. First, the WHODAS-II questionnaire does not take into account some of the unique social issues that occur in adolescence. In their study of individuals at ultra-high risk, Cornblatt et $a l^{7}$ employed two new, broad measures (social and role scale) based on the Social and Occupational Functioning Assessment Scale (SOFAS) and GAF respectively to identify disability, incorporating specific issues such as peer acceptance and dating. An additional consideration of these scales in future research may help to decide whether these are superior to the WHODAS-II in younger samples and/or whether they further contribute to improvements in psychosis prediction.

Second, a methodological issue must be considered. As fitted models always perform in an 'optimistic manner' ${ }^{39}$ in the model-development data, cross-validation in an independent sample is needed to control for tailor-made modelling. Although sample splitting in theory is an option for model validation in large samples, the limited number of transitions did not allow it for statistical reasons. Existing or future samples of comparable size and risk definition are required to validate our findings.

Another potential limitation concerns the 9-month gap in between assessments that may have introduced some inaccuracies in recall, particularly of transition. Indeed, some participants may have had some difficulties in distinguishing their attenuated symptoms from full-blown psychotic symptoms after several months, whereas others may have failed to recall a past psychotic episode at the time of the interview. This latter possibility, however, seems unlikely as researcher staff were trained to probe for transition at follow-up assessments. Additionally, if the participant had not remained in the care of the specialised centre but was back-referred, the referring practitioner as well as the participant and his/her family had been asked to re-establish contact as soon as they suspected psychosis or if the mental state of the individual deteriorated notably.

Finally, once participants made a transition to a psychosis, they were not included in follow-up assessments of the WHODAS-II. Thus it will not be possible to further examine the course and severity of disability after the onset of psychoses. Addressing this issue in future research is recommended. 
In conclusion, our study gives further evidence that a decline in social functioning may be a risk factor for a first psychosis within samples clinically at high risk. $^{13,15}$ In combination with other predictors (neurobiological or psychopathological parameters), social disability measures may make a valuable contribution to a more accurate prediction of first psychotic episodes.

Eva Velthorst, MSC, Dorien H. Nieman, MSC, PhD, Don Linszen, MD, PhD, Hiske Becker, MD, Lieuwe de Haan, MD, PhD, Department of Psychiatry, Academic Medical Center, University of Amsterdam, Amsterdam, The Netherlands: Peter M. Dingemans, PhD, Mediant, Enschedé, The Netherlands; Max Birchwood DSC, Paul Patterson, PhD, School of Psychology, University of Birmingham, Birmingham, UK; Raimo K. R. Salokangas, MD, PhD, MSC, Markus Heinimaa, MD, PhD, Department of Psychiatry, University of Turku, Turku, Finland; Andreas Heinz, MD, PhD, Department of Psychiatry and Psychotherapy, Charité University Medical Center, Berlin, Germany; Georg Juckel, MD, PhD, Department of Psychiatry, Psychotherapy and Psychosomatic Medicine, Ruhr-University Bochum, Bochum Germany; Heinrich Graf von Reventlow, Dipl-Psych, MA, Department of Psychiatry, Psychotherapy and Psychosomatic Medicine, Ruhr-University Bochum, Bochum, and Department of Psychiatry and Psychotherapy, University of Cologne, Germany; Pau French, PhD, Department of Psychiatry, Greater Manchester West Mental Health Trust and School of Psychological Sciences, University of Manchester, Manchester, UK; Helen Stevens, PhD, Department of Psychiatry, Greater Manchester West Mental Health Trust, Manchester, UK; Frauke Schultze-Lutter, PhD, University Hospital of Child and Adolescent Psychiatry, University of Berne, Berne, Switzerland Joachim Klosterkötter MD, PhD, Stephan Ruhrmann, MD, PhD, Department of Psychiatry and Psychotherapy, University of Cologne, Cologne, Germany

Correspondence: D. Linszen, MD, PhD, Academic Medical Center, Department of Psychiatry, Meibergdreef 5, 1105 AZ Amsterdam, The Netherlands. Email: d.h.linszen@amc.uva.n!

First received 28 Nov 2009, final revision 1 Apr 2010, accepted 10 Jun 2010

\section{Funding}

This study was funded within the 5th Framework Programme 'Quality of Life and Management of Living Resources' of the European Commission, Action line 10.1 'Public Health' (grant QLG4-CT-2001-01081). Additional local funding was provided by the Health Research Council of The Netherlands (Zorgonderzoek Nederland/NWO-Medische Wetenschappen, project \# 2630.0001), the Social Insurance Institution of Finland (Dnro 12-26-2006) and by the Medical Faculty of Cologne (Köln Fortune Program).

\section{Acknowledgements}

The International Advisory Board 'European Prediction of Psychosis' (EPOS) group comprises: Patrick D. McGorry, Australia; Thomas H. McGlashan, USA; Martin Knapp, UK.

The authors thank the following scientists for their work for EPOS: Reinaud van der Fliert, MSC, Rianne Klaassen, MD (Department of Psychiatry, AMC, University of Amsterdam, the Netherlands); Heinz Picker, PhD, Meike Neumann, Dipl-Psych, Anke Brockhaus-Dumke, MD, Ralf Pukrop, PhD (Department of Psychiatry \& Psychotherapy/ FETZ, University of Cologne, Cologne, FRG); Tanja Svirskis, MD, PhD, Jukka Huttunen, BM, Tiina Laine, MSc, Tuula Ilonen, $\mathrm{PhD}$, Terja Ristkari, MA, Jarmo Hietala, MD, PhD, (Department of Psychiatry, University of Turku, Turku, Finland); Amanda Skeate, DClin (ED:IT, Early Intervention Service, Birmingham, UK); Yehonala Gudlowski, Dipl-Psych (Charité, Berlin, FRG); Seza Ozgürdal, Dipl-Psych, Henning Witthaus, MD (Charité, Berlin, and Ruhr-University, Bochum, FRG); Shôn Lewis, $\mathrm{MD}$, PhD, Antony Morrisson, PhD (School of Psychological Sciences, University of Manchester, Manchester, UK).

\section{References}

1 Wiersma D, Wanderling J, Dragomirecka E, Ganev K, Harrison G, van der Heiden W, et al. Social disability in schizophrenia: its development and prediction over 15 years in incidence cohorts in six European centres. Psychol Med 2000; 30: 1155-67.

2 Burns T, Patrick D. Social functioning as an outcome measure in schizophrenia studies. Acta Psychiatr Scand 2007; 116: 403-18.

3 Chopra P, Herrman H, Kennedy G. Comparison of disability and quality of life measures in patients with long-term psychotic disorders and patients with multiple sclerosis: an application of the WHO Disability Assessment Schedule II and WHO quality of Life-BREF. Int J Rehabil Res 2008; 31: 141-9.

4 Juckel G, Schaub D, Fuchs N, Naumann U, Uhl I, Witthaus $H$, et al. Validation of the Personal and Social Performance (PSP) Scale in a German sample of acutely ill patients with schizophrenia. Schizophr Res 2008; 104: 287-93
5 Chwastiak L, Von Korff M. Disability in depression and back pain. Evaluation of the World Health Organization Disability Assessment Schedule (WHODAS II) in a primary care setting. J Clin Epidemiol 2003; 56: 507-14.

6 Gureje O, Herrman H, Harvey C, Morgan V, Jablensky A. The Australian National Survey of Psychotic Disorders: profile of psychosocial disability and its risk factors. Psychol Med 2002; 32: 639-47.

7 Cornblatt BA, Auther AM, Niendam T, Smith CW, Zinberg J, Bearden CE, et al. Preliminary findings for two new measures of social and role functioning in the prodromal phase of schizophrenia. Schizophr Bull 2007; 33: 668-702.

8 Häfner H, Nowotny B, Löffler W. When and how does schizophrenia produce social deficits? Eur Arch Psychiatry Clin Neurosci 1995; 246: 17-28.

9 Larsen TK, McGlashan TH. Johannessen JO, Vibe-Hansen L. First-episode schizophrenia: II. Premorbid patterns by gender. Schizophr Bull 1996; 22 257-69.

10 Yung AR, McGorry PD, McFarlane CA, Jackson HJ, Patton GC, Rakkar A. Monitoring and care of young people at incipient risk of psychosis. Schizophr Bull 1996; 22: 283-303.

11 Miller TJ, McGlashan TH, Rosen JL, Somjee L, Markovich PJ, Stein K, et al. Prospective diagnosis of the initial prodrome for schizophrenia based on the Structured Interview for Prodromal Syndromes: preliminary evidence of interrater reliability and predictive validity. Am J Psychiatry 2002; 159: 863-5.

12 Yung AR, Buckby JA, Cotton SM, Cosgrave EM, Killackey EJ, Stanford C, et al. Psychotic-like experiences in nonpsychotic help-seekers: associations with distress, depression, and disability. Schizophr Bull 2006; 32: 352-9.

13 Cannon TD, Cadenhead K, Cornblatt B, Woods SW, Addington J, Walker E, et al. Prediction of psychosis in youth at high clinical risk. Arch Gen Psychiatry 2008; 65: 28-37.

14 Velthorst E, Nieman DH, Becker HE, van der Fliert R, Dingemans PM, Klaassen $\mathrm{R}$, et al. Baseline differences in clinical symptomatology between ultra high risk subjects with and without a transition to psychosis. Schizophr Res 2009; 109: 60-5.

15 Ruhrmann S, Schultze-Lutter F, Salokangas RKR, Heinimaa M, Linszen D, Dingemans $P$, et al. Prediction of psychosis in adolescents and young adults at high risk: results from the Prospective European Prediction of Psychosis Study (EPOS). Arch Gen Psychiatry 2010; 67: 241-51.

16 Klosterkötter J, Ruhrmann S, Schultze-Lutter F, Salokangas RK, Linszen D, Birchwood M, et al. The European Prediction of Psychosis Study (EPOS): integrating early recognition and intervention in Europe. World Psychiatry 2005; 4: 161-7.

17 McGlashan TH, Miller TJ, Woods SW, Rosen JL, Hoffman RE, Davidson L. Structured Interview for Prodromal Syndromes (Version 3.0). PRIME Research Clinic, Yale School of Medicine, 2001.

18 Schultze-Lutter F, Addington J, Ruhrmann S, Klosterkötter J. Schizophrenia Proneness Instrument, Adult Version (SPI-A). Giovanni Fioriti Editore, 2007.

19 Kay SR, Fiszbein A, Opler LA. The positive and negative symptom scale (PANSS). Schizophr Bull 1987; 13: 261-76.

20 Hall RC. Global assessment of functioning. A modified scale. Psychosomatics 1995; 36: 267-75.

21 Hall RC, Parks J. The modified global assessment of functioning scale: addendum. Psychosomatics 1995; 36: 416-7

22 American Psychiatric Association. Diagnostic and Statistical Manual of Mental Disorder (4th edn) (DSM-IV). APA, 1994.

23 First MB, Spitzer RL, Gibbon M, Williams JBW. Structured Clinical Interview for DSM-IV Axis I Disorders (SCID-I). American Psychiatric Publishing, 1997.

24 Chopra PK, Couper JW, Herrman H. The assessment of patients with longterm psychotic disorders: application of the WHO Disability Assessment Schedule II. Aust N Z J Psychiatry 2004; 38: 753-9.

25 Pösl M, Cieza A, Stucki G. Psychometric properties of the WHODAS-II in rehabilitation patients. Qual Life Res 2007; 16: 1521-31.

26 Federici S, Meloni F, Mancini A, Lauriola M, Belardinelli MO. World Health Organisation Disability Assessment Schedule II: contribution to the Italian validation. Disabil Rehabil 2009; 31: 553-64.

27 McKibbin C, Patterson TL, Jeste DV. Assessing disability in older patients with schizophrenia. results from the WHODAS-II. J Nerv Ment Dis 2004; 192 405-13

28 Yung AR, Phillips LJ, Yuen HP, McGorry PD. Risk factors for psychosis in an ultra high-risk group: psychopathology and clinical features. Schizophr Res 2004; 67: 131-42.

29 Yung AR, Nelson B, Stanford C, Simmons MB, Cosgrave EM, Killackey E, et al. Validation of "Prodromal" criteria to detect individuals at ultra high risk of psychosis: 2 year follow-up. Schizophr Res 2008; 105: 10-7.

30 Boeing L, Murray V, Pelosi A, McCabe R, Blackwood D, Wrate R. Adolescentonset psychosis: prevalence, needs and service provision. Br J Psychiatry 2007; 190: 18-26. 
31 Becker T, Leese M, McCrone P, Clarkson P, Szmukler G, Thornicroft G. Impact of community mental health services on users' social networks. PRiSM Psychosis Study 7. Br J Psychiatry 1998; 173: 404-8.

32 Mason O, Startup M, Halpin S, Schall U, Conrad A, Carr V. Risk factors for transition to first episode psychosis among individuals with 'at-risk mental states'. Schizophr Res 2004; 71: 227-37.

33 Riecher-Rössler A, Gschwandtner U, Aston J, Borgwardt S, Drewe M, Fuhr P, et al. The Basel early-detection-of-psychosis (FEPSY)-study - design and preliminary results. Acta Psychiatr Scand 2007; 115: 114-25.

34 Rössler W, Salize HJ, van Os J, Riecher-Rössler A. Size of burden of schizophrenia and psychotic disorders. Eur Neuropsychopharmacol 2005; 15 399-409.

35 Shapiro DI, Marenco S, Spoor EH, Egan MF, Weinberger DR, Gold JM. The Premorbid Adjustment Scale as a measure of developmental compromise in patients with schizophrenia and their healthy siblings. Schizophr Res 2009; 112: $136-42$.

36 Cornblatt BA, Lencz T, Smith CW, Correll CU, Auther AM, Nakayama E. The schizophrenia prodrome revisited: a neurodevelopmental perspective. Schizophr Bull 2003; 29: 633-51.

37 Salokangas RKR, Heinimaa M, Svirskis $\mathrm{T}$, Laine $\mathrm{T}$, Huttunen J, Ristkari $\mathrm{T}$, et al and the EPOS Group. Perceived negative attitude of others as an early sign of psychosis. Eur Psychiatry 2009; 24: 233-8.

38 Herrman $\mathrm{H}$, Hawthorne G, Thomas R. Quality of life assessment in people living with psychosis. Soc Psychiatry Psychiatry Epidemiol 2002; 37: 510-8.

39 Hosmer DW, Lemeshow S. Applied Logistic Regression (2nd edn). John Wiley \& Sons, 2000.

\section{psychiatry in the Old Testament}

\section{Paranoia in the Psalms}

\section{George Stein}

The psalmists sometimes wrote about the 'enemies' and the 'evil-doers' who sought their destruction. However, a close reading of these verses suggests that at least in some instances the psalmist is describing his own paranoid ideation or possibly even paranoid delusions rather than real enemies. Thus, in Psalm 31 there is a description of paranoia, threats conspiracy, fears of being killed and auditory hallucinations.

Ps. 31:13 'For I hear whispering threats from roundabouts while they conspire against me. They scheme to take my life.'

Malign thoughts attributed to others, combined with fears of being killed and a feeling of being watched are described in Psalm 56.

Ps. 56:5 'All day long they seek to injure my cause, All their thoughts are against me for evil, They stir up strife, they watch my steps, as they hoped to have my life'.

Such thoughts may have occurred in the context of a depression because a few verses later on the psalmist writes: 56:8 'You have kept count of my tossings, put my tears in your bottle, Are they not in your records?' The combination of a paranoid illness and depressive symptoms suggest this writer might have been suffering from a psychotic depression. Paranoid ideas of reference with feelings that others are talking about them are given in Psalms 22 and 69.

Ps. 22:7 'All who see me mock at me, they make mouths at me, they shake their heads.' Ps. 69:12 'I am the subject of gossip for those who sit in the gates, and drunkards make songs about me.' A little further on in Psalm 69 there is a description of delusions of being poisoned, combined with a rare psychotic symptom of gustatory hallucinations where the person complains of an altered sense of taste.

Ps. 69:21 'They gave me poison for my food, and for my thirst they gave me vinegar to drink.' It is of course possible that the author was given vinegar to drink, but unlikely that he was given poison for his food because he would have been dead or too ill to write about it. An altered sense of taste is often combined with delusions of being poisoned and this particular combination occurs in paranoid illnesses, especially among the elderly.

Theologians have usually considered that the persecution described by the psalmists was real but have been puzzled by who might lie behind it, as well as what its sociocultural significance might have been. Yet the thoughts and actual words used in these verses echo strongly the sentiments expressed by patients with paranoia and delusions. 